\title{
AUTOLOGOUS HEMATOPOIETIC STEM CELL TRANSPLANTATION IN ITS MAIN INDICATIONS: A SINGLE-CENTER, RETROSPECTIVE STUDY OF 30 YEARS
}

\author{
Bruna Franco Massa, Leonardo Javier Arcuri, Cinthya Corrêa da Silva, Andreza Alice Feitosa Ribeiro, \\ Mariana Nassif Kerbauy, Nelson Hamerschlak
}

All authors from Hospital Israelita Albert Einstein

Corresponding author: Nelson Hamerschlak -hamer@einstein.br

\begin{abstract}
Objective: Autologous hematopoietic stem cell transplantation is widely used in patients with hematological cancers and in some solid tumors. We aimed to describe the transplant procedures performed in a single institution along 30 years.
\end{abstract}

Methods: We describe retrospectively the autologous transplants performed from 1987 to 2016 for: acute myeloid leukemia (AML), Hodgkin (HL) and non-Hodgkin lymphoma (NHL), and multiple myeloma (MM).

Results: We analyzed 378 consecutive patients, all with neutrophil engraftment, which was faster with higher CD34 counts $(p=0.0001)$ and slower in patients with AML $(p=0.003)$. Fiveyear overall survival (OS) was $61 \%$. Receiving transplant in the most recent period (20082017) was a protective factor $(p<0.0001)$. For $M M$, the incidence of relapse was significantly higher in patients not achieving a partial response (hazard ratio, HR=4.02, $p=0.03$ ). For lymphomas, both patients with partial response $(p=0.003)$ and refractory $(p=0.007)$ had higher relapse rates. The 5-year incidence of disease relapse was $42 \%$ for $\mathrm{AML}, 49 \%$ for $\mathrm{MM}, 41 \%$ for $\mathrm{HL}$ and $41 \%$ for NHL ( $p=0.88$ ). Non-relapse mortality was $13 \%$ in 1 year.

Conclusion: There was an improvement in the outcomes of patients undergoing autologous transplants for oncological and onco-hematological diseases across the last 30 years in our institution.

Keywords: Hematopoietic stem cell transplantation. Bone marrow transplantation. HSCT.

\section{INRODUCTION}

Autologous hematopoietic stem cell transplantation (auto-HSCT) is a technique widely used in patients with hematological cancers and some solid tumors. It is also called high-dose chemotherapy with hematopoietic stem-cell support or, simply, autologous bone marrow transplantation. The technique consists of the collection of hematopoietic stem cells from the patient, administration of high-dose chemotherapy, followed by the infusion of previously collected hematopoietic stem-cells. Unlike allogeneic transplantation, in autologous transplantation, there is no need for a donor because the patient himself/herself is the donor.
The number of hematopoietic stem cell (HSCT) transplants has gradually increased over the years. In 1985 , it was limited to 10,000 transplants worldwide, ten years later it accounted for around 100,000 transplants, increasing to 500,000 in 2005 , and doubled to around one million HSCT by the end of 2012.1 The availability of resources and evidence and the positive regulatory environment was associated with the high number of transplants.

In Brazil, autologous HSCT has been practiced in large hospital centers for at least 30 years, when autologous HSCT was established as part of the rescue 
treatment, with curative intent, for patients with relapsed lymphomas. It has also been incorporated into the first-line treatment of multiple myeloma, with the aim of increasing survival.[2,3] Of the total of 2,794 stem cell transplants (HSCT) performed in Brazil in 2017, 59.7\% were autologous, which shows the current importance of this type of transplant in the treatment of onco-hematological diseases.[4]

The objectives of this study are to describe the characteristics of autologous transplants performed for 30 years in a single institution and to analyze the results of autologous transplantation in the most frequent diseases.

\section{METHODS}

This is an observational retrospective cohort study, which included all patients who underwent autologous HSCT between June 1987 and December 2016 at the HSCT unit of a philanthropic hospital. Only patients with multiple myeloma (MM), non-Hodgkin lymphoma (NHL), Hodgkin lymphoma (HL) and acute myeloid leukemia (AML) were included in the analysis of results. The study was approved by the local Ethics Committee. The Ethics Committee waived the need to sign a specific consent form for this study.

The data for this study were collected from the patients' medical records and data reported by the hospital to the Center for International Blood and Marrow Transplant Research (CIBMTR).

Demographic data, such as age and gender, were collected. The following clinical data were also computed: underlying disease, disease status, source of stem cells for transplantation, number of cells infused and performance status. The primary outcome was death. Secondary outcomes were the time for neutrophil and platelet grafting and relapse. The disease condition (status) before transplantation was classified as complete remission, partial remission or with refractory disease.

The characteristics of the patients were described as absolute and relative frequencies. The overall survival (OS) and disease-free survival (DFS) curves were estimated using the Kaplan-Meier method and compared using the log rank test.

For each disease, hazard ratios (HR) were estimated with the respective $95 \%$ confidence intervals, using a single and multiple Cox proportional hazard model. A twotailed $p$-value less than $5 \%$ was considered statistically significant. All analyses were made in $\mathrm{R}$, version [3.6.1].

\section{RESULTS}

Since the first autologous HSCT in the institution, in 1987, until December 2016, 583 autologous transplants were performed in 526 patients. Of these, 378 were transplanted for multiple myeloma (MM), acute myeloid leukemia (AML), Hodgkin lymphoma (HL) or non-Hodgkin lymphoma (NHL). The characteristics of the patients and the first transplants are shown in Table 1. Briefly, the median age was 43 years, 56\% were men, and the most common diagnosis was MM.

All patients had neutrophil engraftment, at a median of 10 days. Factors related to faster recovery were the number of infused CD34 (hazard ratio, $\mathrm{HR}=1.05$ for each increase in $1 \times 10 \mathrm{E} 6 / \mathrm{kg}, \mathrm{p}=0.0001$ ) and, for slower recovery, diagnosis of $A M L(H R=0.33, p=$ 0.003 , compared with MM).

With a median follow-up of 6.4 years, the 5-year overall survival (OS)was $61 \%$. Survival was significantly worse in patients with non-Hodgkin's lymphoma (Figure 1). In the multivariate analysis, both Hodgkin's lymphoma ( $H R=3.02, p=0.0006)$ and non-Hodgkin's lymphoma ( $\mathrm{HR}=2.00, \mathrm{p}=0.0003)$ were associated with worse survival. Age was also a poor-prognosis factor $(H R=1.04$, for each year older, $p<0.0001)$. Transplantation in the most recent period (2008 - 2017) was a protective factor $(H R=0.42$, $\mathrm{p}<0.0001)$.

The 5-year incidence of disease relapse was $42 \%$ for AML, $49 \%$ for $M M, 41 \%$ for $\mathrm{HL}$ and $41 \%$ for $\mathrm{NHL}$ ( $p=$ 0.88 ). For $M M$, the incidence of relapse was significantly higher in patients who did not achieve a partial response $(H R=4.02, p=0.03)$. For lymphomas, both patients who achieved partial response $(\mathrm{HR}=$ $5.16, p=0.003)$ and those who were refractory $(H R=$ $5.06, p=0.007$ ) had higher relapse rate.

Progression-free survival (PFS) was $41 \%$ at 5 years, with no difference between diagnoses (44\% for $A M L, 39 \%$ for $M M, 51 \%$ for $L H$, and $41 \%$ for $N H L ; ~ p$ $=0.50)$. In the multivariate analysis, the factors of poor prognosis were age ( $H R=1.03$ for each additional year, $p=0.003)$, partial remission $(H R=3.22$, $p=0.0003)$ and refractory disease $(H R=4.73, p=$ 0.003 ) for lymphomas. For $M M$, only pre-transplant disease status (HR $=2.11, p=0.01$ for partial remission, and $H R=19.5, p<0.0001$ for patients who did not achieve partial response) were identified as risk factors.

Non-relapse mortality was $13 \%$ in 1 year. We did not find any factors associated with non-relapse mortality. 


\section{DISCUSSION}

This analysis of the results of a single autologous transplant center in multiple myeloma, non-Hodgkin's lymphoma, Hodgkin's lymphoma and acute myeloid leukemia is one of the largest in the world. $[5,6,7,8,9]$ It shows that the modality rendered an overall survival of $61 \%$. There were no grafting failures and the times for neutrophil and platelet engrafting were compatible with literature data.[10]

The indication of autologous transplantation for patients with multiple myeloma should be maintained even with the advent of novel treatments. Several studies show that, even with the new proteasome inhibitors and pre-transplant immunomodulators, autologous HSCT increased progression-free survival, especially in patients younger than 70 years old. At the American Association of Hematology last meeting, the importance of the procedure for this group of patients was also demonstrated.[9,11] Current studies comparing transplanted versus non-transplanted patients corroborate our findings. They show an advantage for autologous transplantation as a complement to treatment instead of following with observation or even maintenance. $[9,12,13]$

Possibly, one of the reasons for the success is the adequate selection of patients in conditions to be transplanted, with good functional status. All patients selected for transplantation in this sample were generally in good clinical condition, usually less than 75 years old and without major comorbidities. In our institution, for patients older than 65 years old (which represented $11 \%$ of patients), we use the Comprehensive Geriatric Assessment. $[14,15]$ Still, mortality was higher in older patients. However, when considering only mortality up to 100 days, age was not a prognostic factor. Also, we have seen an improvement in overall survival in the most recent period.

Our results showed that patients with multiple myeloma with a median age of 58 years had 39\% disease-free survival at 5 years. The overall survival was $69 \%$. This data is compatible with other findings in the literature.[16] As with most diseases, we also demonstrated that patients' pre-transplant disease status is fundamental in the outcome. That is, patients with stable disease have worse disease-free survival.[16]

Patients with non-Hodgkin's lymphoma are usually transplanted as part of the treatment of relapsed chemosensitive patients. The cure rate of patients with aggressive $B$ lymphoma in first remission var- ies from $50 \%$ to $90 \%$ depending on the prognostic indexes.[17] Our results show that, following relapse, $41 \%$ of the patients remained in complete remission after 5 years. The prognosis of patients who were not at complete remission was poor and even worse for refractory patients. CD19+ Non-Hodgkin lymphomas are discussed for their future replacement by other methods of cell therapy, such as the chimeric antigen receptor T-cells (CAR-T cells) against CD19, but this is not yet established.

This situation is similar to that with Hodgkin's lymphomas. These have high cure rates with the initial treatments, ranging from 75 to $90 \%$. In relapses, autologous transplantation is a treatment option, and our data show that $51 \%$ remained in complete remission in five years. Literature data point to 40 to $70 \%$, depending on the prognostic index.18,19 In our sample, we did not classify patients because it is a retrospective study in which data were not always available. The only data we had was pre-transplant status. As with multiple myeloma, autologous transplantation in Hodgkin's and non-Hodgkin's lymphoma continues to be used even with the advent of new therapies and transplant modalities.

In the case of acute myeloid leukemia, the situation is different, as this modality, more defended by the Europeans and less by the Americans, had only one reference at the ASH 2018 meeting, presented on a poster precisely by Europeans. In that study, they suggest that patients who achieve complete remission after induction, depending on their cytogenetics and molecular factors, should undergo allogeneic transplantation or four to five consolidations or one to two consolidations and autologous transplantation.[20,21] These patients are those with good prognosis or intermediate prognosis who do not have a compatible donor. In our population, the disease-free survival in 5 years was $44 \%$, and the global was $65 \%$. The choice between several consolidations versus autologous transplantation in this group of patients is still controversial and is the subject of several comparative studies.[22,23] In patients at intermediate risk, data showing that haploidentical transplants are similar to allogeneic transplants from unrelated donors end up endorsing its use in this category in detriment of autologous ones.[24,25]

The results showing a $50 \%$ long-term survival rate agree with data from the literature, which reveals the recurrence rate as a major concern in this type of transplant compared to allogeneic transplants. In these, the leading cause of death is procedure toxicity, with a higher rate of infections and the presence 
of graft versus host disease.[26] Patients with poor prognoses, such as those with complex cytogenetics or presence of FLT3 mutated gene (tyrosine kinase 3 Fms-related), if they are not submitted to allogeneic transplantation, have a high chance of recurrence of the disease in a short period.[27] On the other hand, patients with good prognostic cytogenetics, such as $\mathrm{t}[8: 21]$ or inv16, and those with normal karyotype, with negative FLT3 and positive NPM1, would have a higher risk with allogeneic transplantation28, which presents greater toxicity compared to intensive chemotherapy such as consolidation or autologous transplantation. Only randomized studies will demonstrate the superiority or otherwise of autologous transplantation over chemotherapy in these low-risk or intermediate-risk patients.[8]

In summary, the profile and historical path of autologous transplants for oncological and onco-hematological diseases performed in the last 30 years in a Brazilian institution demonstrated evolution according to the medical literature, giving the possibility of recovering a significant number of patients with Hodgkin's lymphoma, non-Hodgkin lymphoma, multiple myeloma and acute myeloid leukemia. The continuous study of the performance of autologous transplants in the light of new therapies allows reframing their indications when compared to new therapies. Thus, even with the advent of new therapies, the indications for autologous first-line transplantation for young and fit patients with multiple myeloma remain, and their use in relapsed or refractory patients with Hodgkin's and non-Hodgkin's lymphoma as second-line consolidation of treatment. However, in acute myeloid leukemia, autologous transplants would only have some indication in patients with a favorable prognosis. Only prospective studies will show whether its use exceeds the performance of several cycles of consolidation with cytarabine.

TABLE 1 - Patients' characteristics

\begin{tabular}{|c|c|}
\hline & TOTAL \\
\hline Total & 526 \\
\hline Age - mean (SD) & $44.6(17.9)$ \\
\hline \multicolumn{2}{|l|}{ Gender } \\
\hline Male & $292(55.5 \%)$ \\
\hline Female & $234(44.5 \%)$ \\
\hline \multicolumn{2}{|l|}{ Diagnosis } \\
\hline AML & $44(8.4 \%)$ \\
\hline MM & $159(30.3 \%)$ \\
\hline $\mathrm{HL}$ & $45(8.6 \%)$ \\
\hline $\mathrm{NHL}$ & $129(24.6 \%)$ \\
\hline Others & $148(28.2 \%)$ \\
\hline \multicolumn{2}{|l|}{ Status prior to transplant } \\
\hline Complete remission & 97 (36.3\%) \\
\hline Partial remission & $137(51.3 \%)$ \\
\hline REF & $33(12.4 \%)$ \\
\hline \multicolumn{2}{|l|}{ Stem cell source } \\
\hline PBSC & $451(85.7 \%)$ \\
\hline BM & $25(4.8 \%)$ \\
\hline $\mathrm{BM}+\mathrm{PBSC}$ & $50(9.5 \%)$ \\
\hline CD34 - mean (SD) & $5.9(4.5 \%)$ \\
\hline \multicolumn{2}{|l|}{ Period } \\
\hline 1987-1997 & $144(28.6 \%)$ \\
\hline 1998-2007 & $201(40 \%)$ \\
\hline $2008-2017$ & $158(31.4 \%)$ \\
\hline
\end{tabular}

$\mathrm{SD}$ = standard deviation; $\mathrm{AML}=$ acute myeloid leukemia; $\mathrm{MM}=$ multiple myeloma; $\mathrm{HL}=$ Hodgkin lymphoma; $\mathrm{NHL}=$ non-Hodgkin lymphoma; $\mathrm{PBSC}=$ peripheral blood stem cell; $\mathrm{BM}=$ bone marrow 


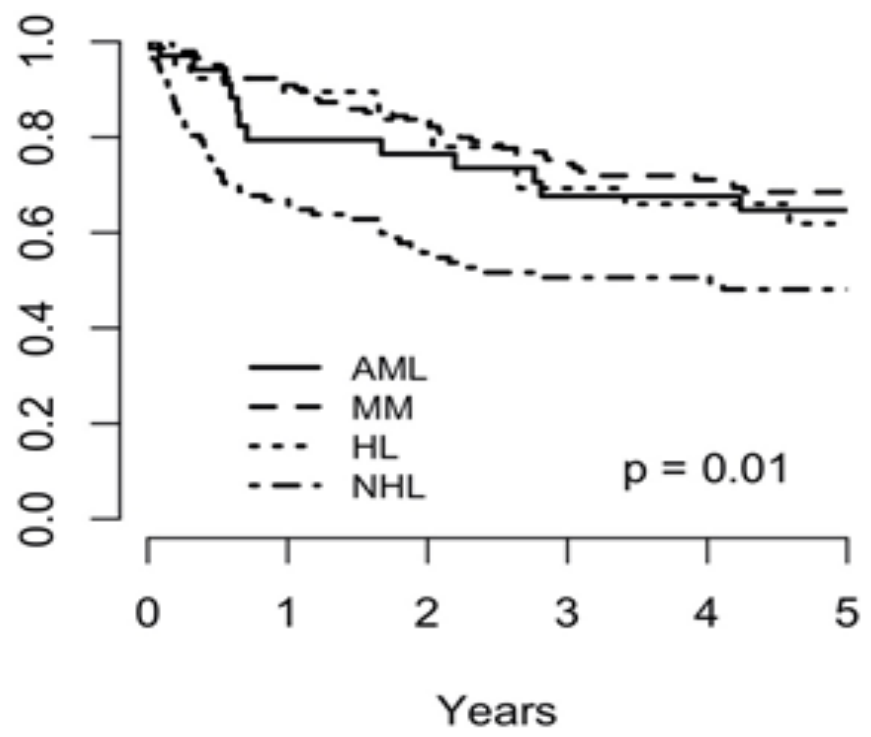

GRAPHIC 1 - Overall survival

\section{REFERENCES}

1. Gratwohl A, Pasquini MC, Aljurf M, Atsuta Y, Baldomero $\mathrm{H}$, Foeken $\mathrm{L}$, et al. One million haemopoietic stem-cell transplants: a retrospective observational study. Lancet Haematol. 2015v.2, n.3, p.e91-100.

2. Yoon JH, Kim HJ, Park SS, Jeon YW, Lee SE, Cho BS, et al. Clinical Outcome of Autologous Hematopoietic Cell Transplantation in Adult Patients with Acute Myeloid Leukemia: Who May Benefit from Autologous Hematopoietic Cell Transplantation? Biol Blood Marrow Transplant [Internet]. 2017n.23, v.4,p.588-97. Available from: http:// dx.doi.org/10.1016/j.bbmt.2017.01.070

3. Duarte FB, De Brito Fernandes MG, Kaufmann J, Barroso KSN, De Vasconcelos Leitão JP, De Souza Pitombeira Araujo BSG, et al. Hodgkin's Lymphoma - Evaluation of patients submitted to Autologous transplantation of hematopoietic cells in the Hematology Service of the Hospital Walter Cantídio - Fortaleza, Brazil. Rev Assoc Med Bras. 2016v.62, p.34-8.

4. Registro Brasileiro de TRansplantes. Dimensionamento dos Transplantes no Brasil e em cada estado (2010-2017) [Internet]. [cited 2018 Jun 17]. Available from: http://www.abto.org.br

5. Lévy V, Katsahian S, Fermand JP, Mary JY, Chevret S. A meta-analysis on data from 575 patients with multiple myeloma randomly assigned to either high-dose therapy or conventional therapy. Medicine (Baltimore). 2005;v.84, n.4, p.250-60.

6. Vellenga E, Van Putten WLJ, Van 't Veer MB, Zijlstra JM, Fibbe WE, Van Oers MHJ, et al. Rituximab improves the treatment results of DHAP-VIMDHAP and ASCT in relapsed/progressive aggressive CD20+ NHL: A prospective randomized HOVON trial. Blood. 2008v.111, n.2, p.537-43.

7. Moskowitz $\mathrm{CH}$, Kewalramani T, Nimer SD, Gonzalez M, Zelenetz AD, Yahalom J. Effectiveness of high dose chemoradiotherapy and autologous stem cell transplantation for patients with biopsy-proven primary refractory Hodgkin's disease. BrJ Haematol. 2004v.124, v.5, p.645-52.

8. Gorin NC, Giebel S, Labopin M, Savani BN, Mohty $M$, Nagler A. Autologous stem cell transplantation for adult acute leukemia in 2015: Time to rethink? Present status and future prospects. Bone Marrow Transplant. 2015v.50, n.12,p.1495-502.

9. Gay F, Oliva S, Petrucci MT, Conticello C, Catalano $L$, Corradini $P$, et al. Chemotherapy plus lenalidomide versus autologous transplantation, followed by lenalidomide plus prednisone versus lenalidomide maintenance, in patients with multiple myeloma: A randomised, multicentre, phase 3 trial. Lancet Oncol. 2015;v. 16, n. 16, p.1617-29.

10. Hsu YMS, Cushing MM. Autologous Stem Cell Mobilization and Collection. Hematol Oncol 
Clin North Am [Internet]. 2016v.30,n.3, p.57389. Available from: http://dx.doi.org/10.1016/j. hoc.2016.01.004

11. Usmani SZ SE. Treatment approach for young, fit, newly diagnosed multiple myeloma patients. Hematol Am Soc Hematol Educ Program. 2018 n.1, p.97-102.

12. Mahajan S, Tandon N KS. The evolution of stemcell transplantation in multiple myeloma. Ther Adv Hematol. 2018v.9,n.5,p.123-133.

13. Giralt S, Seifter E. Case-based roundtable on treatment approach for young, fit, newly diagnosed multiple myeloma patients. Hematology. 2018;2018n.1,p.103-9.

14. Rodrigues M, Souza PMR, Koch LM, Hamerschlak N. The Comprehensive Geriatric Assessment in Elderly Patients Submitted to Autologousbone Marrow Transplant: A Retrospective Analysis. Biol Blood Marrow Transplant [Internet]. 2018v.24, n.3, p.S146-7. Available from: https:// doi.org/10.1016/j.bbmt.2017.12.100

15. Muffly LS, Kocherginsky M, Stock W, Chu Q, Bishop MR, Godley LA, et al. Geriatric assessment to predict survival in older allogeneic hematopoietic cell transplantation recipients. Haematologica. 2014v.99, n.8,p.1373-9.

16. Barlogie B, Kyle RA, Anderson KC, Greipp PR, Lazarus HM, Hurd DD, et al. Standard chemotherapy compared with high-dose chemoradiotherapy for multiple myeloma: Final results of phase III US intergroup trial S9321. J Clin Oncol. 2006v.24,929-36.

17. lams W, Reddy NM. Consolidative autologous hematopoietic stem-cell transplantation in first remission for non-Hodgkin lymphoma: Current indications and future perspective. Ther Adv $\mathrm{He}$ matol. 2014v.5, n. 5, p.153-67.

18. Akhtar S. High dose chemotherapy and autologous stem cell transplantation in relapsed or refractory Hodgkin lymphoma: Emerging questions, newer agents, and changing paradigm. Hematol Oncol Stem Cell Ther [Internet]. 2017;10(4):272-6. Available from: https://doi. org/10.1016/j.hemonc.2017.05.010

19. Sieniawski M, Franklin J, Nogova L, Glossmann $J P$, Schober T, Nisters-Backes $\mathrm{H}$, et al. Outcome of patients experiencing progression or relapse after primary treatment with two cycles of chemotherapy and radiotherapy for early-stage favorable Hodgkin's lymphoma. J Clin Oncol. 2007v.25, n.15,p. 2000-5.

20. da Rocha Silla LM, Dulley F, Saboya R, Paton E, Kerbauy F, de Moraes Arantes A, et al. Bone marrow transplantation and acute myeloid leukemia: Brazilian guidelines. Rev Bras Hematol Hemoter. 2013v.35, n.1, p. 56-61.

21. Linker CA. Autologous stem cell transplantation for acute myeloid leukemia. Bone Marrow Transplant. 2003v.31, n.9, p.731-8.

22. Heini AD, Berger MD, Seipel K, Taleghani BM, Baerlocher GM, Leibundgut $K$, et al. Consolidation with autologous stem cell transplantation in first remission is safe and effective in AML patients above 65 years. Leuk Res [Internet]. 2017v.53, p.28-34. Available from: http://dx.doi. org/10.1016/j.leukres.2016.12.001

23. Krug, U., Berdel, W., Gale R et al. Increasing intensity of therapies assigned at diagnosis does not improve survival of adults with acute myeloid leukemia. Leukemia [Internet]. 2016v.30, p.1230-1236. Available from: https://www.nature.com/articles/leu201625?proof=true1

24. Di Stasi A, Milton DR, Poon LM, Hamdi A, Rondon G, Chen J, et al. Similar Transplant Outcomes for AML/MDS Patients with Haploidentical versus 10/10 HLA Matched Unrelated and Related Donors. Biol Blood Marrow Transplant. 2014;20(12):1975-81.

25. Ciurea SO, Zhang MJ, Bacigalupo AA, Bashey A, Appelbaum FR, Aljitawi OS, et al. Haploidentical transplant with posttransplant cyclophosphamide vs matched unrelated donor transplant for acute myeloid leukemia. Blood. 2015;126(8):1033-40.

26. van Besien K. Allogeneic transplantation for AML and MDS: GVL versus GVHD and disease recurrence. Hematology Am Soc Hematol Educ Program. 2013;2013(Table 1),p.56-62.

27. Sutamtewagul G, Vigil CE. Clinical use of FLT3 inhibitors in acute myeloid leukemia. Onco Targets Ther. 2018;11:7041-52.

28. Saif A, Kazmi SFA, Naseem $R$, Shah $H$, Butt MO. Acute Myeloid Leukemia: Is That All There Is? Cureus. 2018,v.10, n.8, p.1-7. 